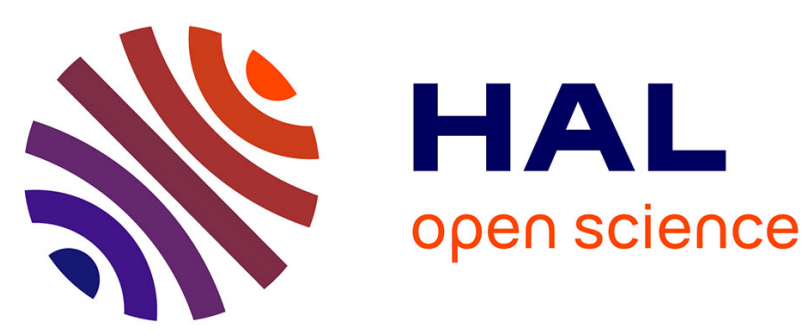

\title{
Application of fuzzy classifier fusion in determining productive zones in oil wells
}

Pedram Masoudi, Behzad Tokhmechi, Majid Ansari Jafari, Behzad Moshiri

\section{To cite this version:}

Pedram Masoudi, Behzad Tokhmechi, Majid Ansari Jafari, Behzad Moshiri. Application of fuzzy classifier fusion in determining productive zones in oil wells. Energy Exploration and Exploitation, 2012, 30 (3), pp.403 - 416. 10.1260/0144-5987.30.3.403 . insu-01382442

\section{HAL Id: insu-01382442 \\ https://hal-insu.archives-ouvertes.fr/insu-01382442}

Submitted on 17 Oct 2016

HAL is a multi-disciplinary open access archive for the deposit and dissemination of scientific research documents, whether they are published or not. The documents may come from teaching and research institutions in France or abroad, or from public or private research centers.
L'archive ouverte pluridisciplinaire HAL, est destinée au dépôt et à la diffusion de documents scientifiques de niveau recherche, publiés ou non, émanant des établissements d'enseignement et de recherche français ou étrangers, des laboratoires publics ou privés. 


\title{
Application of fuzzy classifier fusion in determining productive zones in oil wells
}

\author{
by \\ Pedram Masoudi, Behzad Tokhmechi, Majid Ansari Jafari, \\ Behzad Moshiri \\ reprinted from

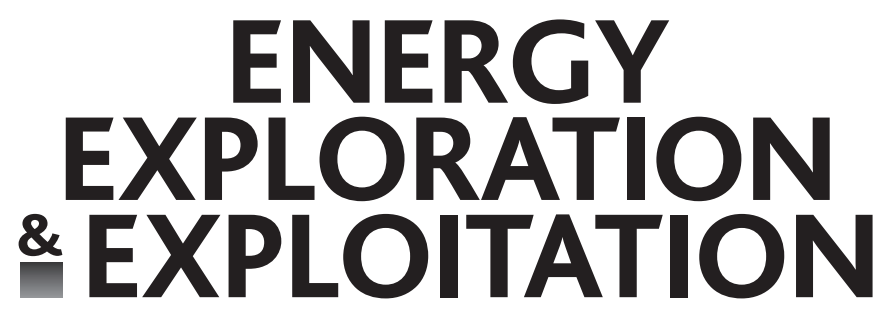

Volume 302012

Number 3

(C) 2012

MULTI-SCIENCE PUBLISHING CO. LTD.

5 Wates Way, Brentwood, Essex CM15 9TB, United Kingdom 


\title{
Application of fuzzy classifier fusion in determining productive zones in oil wells
}

\author{
Pedram Masoudi ${ }^{1 *}$, Behzad Tokhmechi ${ }^{1}$, Majid Ansari Jafari ${ }^{1}$, \\ Behzad Moshiri

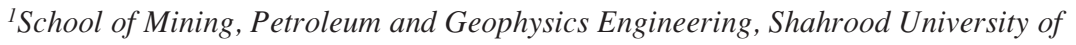 \\ Technology, Iran \\ ${ }^{2}$ CIPCE, IEEE Senior Member, School of Electrical and Computer Engineering, University of \\ Tehran, Iran \\ *Author for Corresponding.Email: masoudip@alumni.ut.ac.ir
}

(Received 14 May 2011; accepted 9 December 2011)

\begin{abstract}
This study is an application of data fusion techniques, especially fuzzy theory, in determining oil producing zones through four nearby wells, located on an oil field in south west of Iran. Two fusing techniques, used here are based on Bayesian and fuzzy theories. At first, two Bayesian classifiers are being constructed by training in two different wells; then a fuzzy operator, called Sugeno discrete integral, is used to fuse outputs of two mentioned Bayesian classifiers. Finally, it is concluded that using fuzzy classifier fusion improves not only certainty and confidence of decision making, but also generalization ability of determining productive zones.
\end{abstract}

Keywords: Pay zone, Data fusion, Fuzzy, Bayesian, Sugeno integral

\section{INTRODUCTION}

Conventionally, petroleum engineers divide whole drilled interval to pay (productive) and non-pay zones. Accuracy of pay determination is critical in estimating Hydrocarbon Initially in Place (HCIIP), which is really important in reservoir evaluation (Masoudi et al., 2011). This crisp pay determination usually is done by picking up some intervals that contain high values of porosity and low values of water saturation and shale percent. To determine productive zones, different approaches have been proposed by researchers till now.

Snyder combined gamma and resistivity logs to determine pay zones, whereas Flower used combination of sonic-shear-wave and resistivity logs to find productive zones (Flower, 1983; Snyder, 1971). In 1984, formation pressure tester was introduced as a quick-look indicator of productive zones (Cooke-Yarborqugh, 1984). To determine pay zones in a dolomitic reservoir, Howell et al. (1992) utilized cut-offs of less than $50 \%$ water saturation and greater than $4 \%$ porosity. In a paper, published in 1996, pay zones in limestone were determined by applying four cut-off parameters, shale percent, porosity, permeability and connate water (Joshi and Lahiri, 1998). 
In 1997, Hassoun et al. (1997) investigated on three applications of NMR logging that one of them was hydrocarbon identification in low contrast resistivity pay zones of sandstones of central Arabia. Deakin and Manan investigated on detecting low contrast pays in a gas reservoir. To do so, they integrated three different datasets: image $\log$ interpretations, conventional $\operatorname{logs}$ and core capillary data (Deakin and Manan, 1998). Worthington proposed a single-universal algorithm to detect different types of low-resistivity pay zones (Worthington, 2000). Mathur et al. were the first researchers, who incorporated geochemical analysis of side-wall cores in detecting net pays (Mathur et al., 2001).

A comprehensive investigation about application of cut-offs in determining net pays was fulfilled by Worthington and Cosentino in 2005. They have collected different combinations of petrophysical cut-offs that have been used by previous researchers from 1980 to 2002 (Worthington and Cosentino, 2005). Jensen and Menke were researchers who investigated about cut-off determination statistically. The method they provided minimizes error of calculating net to gross ratio (Jensen and Menke, 2006). Worthington has another work on determining cut-offs dynamically, i.e. cut-offs determination due to depletion strategy (Worthington, 2008). Detection of pay zones on seismic lines is done for the first time at (Singleton, 2008).

In the last research about crisp net pay determination, different net types are defined, and various applications of net pay in petroleum industry are discussed (Worthington, 2010). But in latest paper about determining productive zones, a novel methodology is developed that identifies productive zones fuzzily. This new pay determination is based on flow equation (Masoudi et al., 2012).

The majority of mentioned works are applied on sandstone reservoirs but the dataset of this investigation belongs to a carbonate reservoir. It is imprecise and sometimes impossible to apply cut-off methods on carbonate rocks, because nature of these rocks is more variable and naturally wilder than sandstones. The novelty of this study is to develop a new methodology in determining net pays not only more precise but also fuzzily by utilizing a fuzzy-based methodology. The methods provided here are based on data fusion techniques.

\section{THE EXPERIMENTAL DATASET}

Integrated dataset of this work consists of conventional wire line well log data, core porosity and well test results of four nearby wells on an oil field, located in Dasht-e Abadan, Iran. The investigation is fulfilled on the interval of Sarvak Formation, whose depth in this field is approximately between $2700 \mathrm{~m}$ to $3400 \mathrm{~m}$. Sarvak is a carbonate type reservoir rock in Iranian oil fields deposited from Albian to Turonian. Table 1 shows a summary of available dataset of this paper. From all the well logs, Corrected Gamma Ray (CGR), Sonic Log (DT), Neutron Porosity (NPHI), Bulk Density (RHOB) and Resistivity Logs of Deep (LLD), Shallow (LLS) and Micro (MSFL) are used but the others are not, because they were not available in all four wells simultaneously. 
Table 1. Summary of datasets, available for this work ("npv" stands for "net pay value").

\begin{tabular}{|c|c|c|c|c|c|}
\hline & & Well 1 & Well 2 & Well 3 & Well 4 \\
\hline \multirow{3}{*}{ 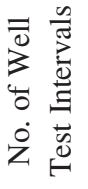 } & $n p v=1$ & 3 & 2 & 4 & 1 \\
\hline & $n p v=2$ & 3 & 0 & 1 & 1 \\
\hline & $n p v=3$ & 0 & 1 & 1 & 1 \\
\hline \multirow{11}{*}{ 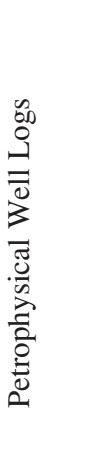 } & CALI & $\checkmark$ & $\checkmark$ & $x$ & $\checkmark$ \\
\hline & GR & $\checkmark$ & $x$ & $\checkmark$ & $\checkmark$ \\
\hline & CGR & $\checkmark$ & $\checkmark$ & $\checkmark$ & $\checkmark$ \\
\hline & DT & $\checkmark$ & $\checkmark$ & $\checkmark$ & $\checkmark$ \\
\hline & NPHI & $\checkmark$ & $\checkmark$ & $\checkmark$ & $\checkmark$ \\
\hline & RHOB & $\checkmark$ & $\checkmark$ & $\checkmark$ & $\checkmark$ \\
\hline & DRHO & $\checkmark$ & $x$ & $\checkmark$ & $\checkmark$ \\
\hline & LLD & $\checkmark$ & $\checkmark$ & $\checkmark$ & $\checkmark$ \\
\hline & LLS & $\checkmark$ & $\checkmark$ & $\checkmark$ & $\checkmark$ \\
\hline & MSFL & $\checkmark$ & $\checkmark$ & $\checkmark$ & $\checkmark$ \\
\hline & PEF & $\checkmark$ & $x$ & $x$ & $\checkmark$ \\
\hline \multicolumn{2}{|c|}{ Core Porosity } & $\checkmark$ & $\checkmark$ & $\checkmark$ & $\checkmark$ \\
\hline
\end{tabular}

\section{METHODOLOGIES}

\subsection{Cut-off method}

In this method, some petrophysical features should be selected to apply specific cut-off values on. The algorithm used here is presented below.

a) Shale volume and water saturation determination from corrected CGR log and Archie relation respectively (Darling, 2005; Johnson and Pile, 2002).

b) Porosity estimation by Artificial Neural Network (ANN) by input log data of CGR, DT LLD, LLS, MSFL, NPHI and RHOB.

c) Selecting horizons that have porosity values higher than $5 \%$, water saturation values less than $40 \%$ and shale volume percent less than $25 \%$ to be considered as pay zones for three wells. For the well no. 2, cut-offs of porosity and water saturation are considered $6 \%$ and $50 \%$ respectively due to recommend of NIOC reports (Deakin and Manan, 1998; Svec and Grigg, 2000; Worthington, 2010; Worthington and Cosentino, 2005).

Cut-off net pay determination method is mainly developed in sandstone reservoirs but due to lack of a specific method for carbonate reservoirs, it is usually utilized in carbonate reservoirs too. Relation between petrophysical parameters in carbonates is more complex than sandstones; therefore, sometimes finding cut-off of features (which is determined from a trend line on cross plot of that feature and another) is uncertain in some degrees in carbonates. 


\subsection{Bayesian classifier}

Bayesian classifier chooses the most probable class for each input vector. This classifier is based on the rule of conditional probability, which is Base theory. The algorithm, used in this investigation is obtained from (Duda et al., 2000), and the formula of Bayesian classifier, modified for this work, is:

$$
P(n p v)=\sum_{i=1}^{n} P\left(n p v \mid d_{i}\right) \times P\left(d_{i}\right)
$$

where " $n p v$ " stands for "net pay value", which can be 0,1 or 2 . $n p v=0$ means that there is no oil production, $n p v=1$ means there is oil production but less than $1500 \frac{\text { bbl oil }}{d a y}$, and $n p v=2$ means there is more than $1500 \frac{\text { bbl oil }}{d a y}$ oil production $d_{i}$ is the $i$-th component of total $n$ components of a specific input vector $\left(d_{1}, d_{2}, d_{3}, \ldots, d_{n}\right)$. $P(n p v)$ and $P\left(d_{i}\right)$ are probabilities of occurrence of specific values of $n p v$ and $d_{i}$ respectively.

Bayesian classifier is trained on well test intervals, and $n p v$ values are obtained from well tests results. $70 \%$ of data of each tested interval is considered for training and the remnant is considered for testing the classifier.

\subsubsection{Feature selection}

To select input features for Bayesian classifier, Bayesian Network is used. It is a directed acyclic graph that shows dependency relation between different features (Niedermayer, 2008). To train the graph, $K 2$ algorithm is used, which is a score-based method (Lauría, 2008). To run $K 2$ algorithm, features should be fed to the algorithm in the order that shows dependency relation between them.

Bayesian Network graph distinguishes direct and indirect effective features on a specific parameter, which is here pay zone. By the means of this graph, input features for classification process is selected among others. For further study about $K 2$ algorithm the reader is referred to (Doguc and Ramirez-Marquez, 2009).

\subsection{Fuzzy integral}

In 1974, Sugeno introduced the concept of fuzzy integral in his $\mathrm{PhD}$ thesis (Grabisch et al., 1992). It is reported that the results of fuzzy integrals as a classifier fusion is great (Kuncheva, 2004). A non-linear operator, called Sugeno discrete integral, is used here to fuse outputs of Bayesian classifiers, which it's algorithmic, introduced in the following:

a) For a given input vector (x), which its components are outputs of $n$ classifiers going to be fused, sort the components in order to set the first component as the highest value and last component as the lowest value i.e.:

$$
\mathbf{x}=\left[x_{1}, x_{2}, \quad, x_{n}\right] \rightarrow \mathbf{x}_{s}=\left[x_{s_{1}}, x_{s_{2}}, \quad, x_{s_{n}}\right] \text { that }: x_{s_{1}}>x_{s_{2}}>>x_{s_{n}}
$$

b) Fuzzy densities of components of input vector are arranged according to sorted input vector $\left(\mathbf{x}_{s}\right)$, i.e.,

$$
g_{s}=\left[g_{s_{1}}, g_{s_{2}}, \ldots, g_{s_{n}}\right]
$$


c) Calculate $\lambda>-1$ by the formula:

$$
\lambda+1=\prod_{t=1}^{n}\left(1+\lambda g_{s_{t}}\right)
$$

d) Set $g(1)=g_{s_{1}}$, and for $t=2$ to $n$, calculate $g(i)$ recursively:

$$
g(t)=g_{s_{t}}+g(t-1)+\lambda g_{s_{t}} g(t-1)
$$

e) Calculate output of Sugeno integral as output of fusing classifiers:

$$
\mu(\mathrm{x})=\max _{t=1: n}\left\{\min \left\{x_{s_{t}}, g(t)\right\}\right\}
$$

\subsection{Performance assessment}

To evaluate and compare preciseness of utilized methods, confusion matrix and Classification Correctness Rate (CCR) are used. Confusion matrix is a matrix that its $(j, i)$ element is the number of vectors that belong to $i$ th real class but classified in the jth class (Theodoridis and Koutroumbas, 2003). Classification Correctness Rate (CCR) is summation of corrected classified elements (on the trace of confusion matrix), divided by summation of all the elements of this matrix.

\section{RESULTS}

\subsection{Results of cut-off method}

After applying the algorithm of cut-off method on the mentioned dataset, productive zones are determined crisply (pay or non-pay). Figure 1 shows obtained results:

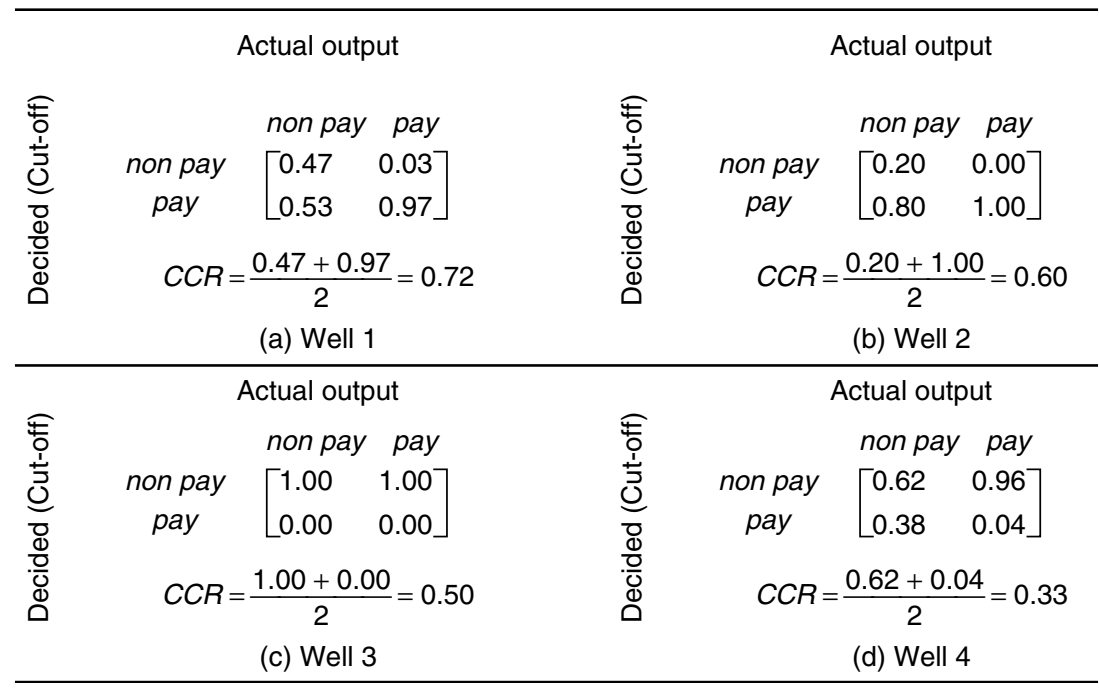

Figure 1. Confusion matrices and CCR values of determining productive zones by cut-off methodology in all the wells. 


\subsection{Input selection for bayesian classifiers}

Input of Bayesian classifiers are selected among those well log data, available in all wells. A combined feature (LLD/LLS) is added to them because it can be an attribute, related to permeability, which is an important property for productive zones. At first, cross plots of available well logs are sketched (Figure 2); then among these petrophysical parameters, those which are highly correlated are determined. DT, RHOB and NPHI are highly correlated with each other, in addition, LLD and LLS are highly correlated with each other too. Hence; DT and RHOB are removed in the presence of NPHI, and LLS is removed too in the presence of LLD. Then, NPHI, LLD, CGR and LLD/LLS are selected to construct Bayesian Network to investigate dependency of net pay on them.

\subsubsection{Bayesian networks}

To construct Bayesian Network, $K 2$ algorithm is used. The order of inputs to feed the algorithm was as below from left to right, which shows dependency relation between the inputs:

\section{CGR- NPHI- LLD- LLD/LLS- Net Pay}

This order was selected because:

- CGR is related to shale percent, which affects total porosity (NPHI) a lot.

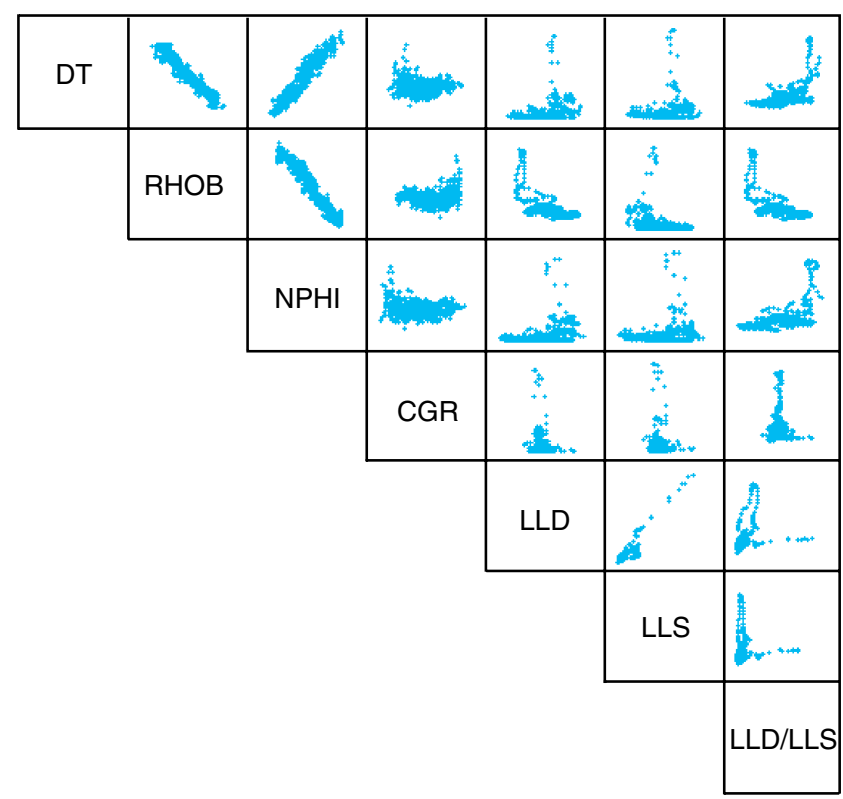

Figure 2. Cross plots of input candidates. 
- $\quad$ NPHI is an effective parameter on permeability and capillary pressure, which are both effective on hydrocarbon migration, hence; on LLD value.

- Of course LLD/LLS is affected by LLD due to its mathematical relation.

- Net pay value is located at the end of this order to check other parameters effect on it.

Constructed Bayesian Networks are shown in Figure 3. In this figure, LLD/LLS is the most effective parameter on the net pay value in all the wells, and LLD is in the next priority. So, two parameters, LLD/LLS and LLD are selected as input features of Bayesian classifier.

\subsection{Training bayesian classifiers}

Bayesian classifier is trained two times: in wells 3 and 4 respectively. Because of lack of well test result with net pay values ( $n p v)$ equal to three and two in wells 1 and 2 respectively, it is impossible to calculate all three priory knowledge values in these two wells. Hence, there are two trained Bayesian classifier, one of them is trained in well 3 (called Bayesian-3), and another is trained in well 4 (called Bayesian-4). Confusion matrices and CCR values of pay zone determination by Bayesian- 3 and Bayesian- 4 are presented in Figures 4 and 5 respectively.

Now, there are two Bayesian classifiers whose outputs differ a lot. This disagreement is obvious not only in confusion matrices and CCR values (Figures 4 and 5), but also in the way, they classify whole Sarvak interval (Fig. 6). For example output of Bayesian-3 is more pessimistic in comparison to output of Bayesian-4. In addition, Bayesian-4 shows a producing interval at depths more than $3000 \mathrm{~m}$, whereas Bayesian-3 does not show any significant producing interval beneath $3000 \mathrm{~m}$ (Fig. 6). So, to come on an agreement about Sarvak Formation, something should be done.

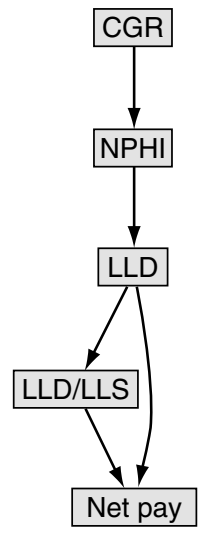

Well 1

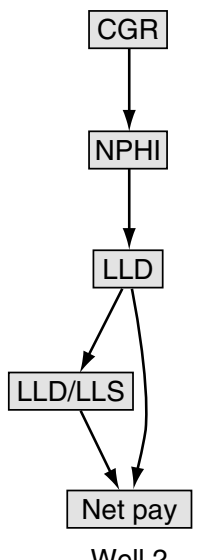

Well 2

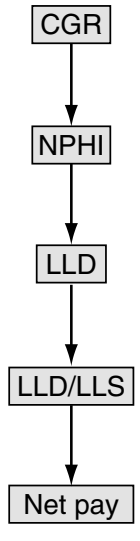

Well 3

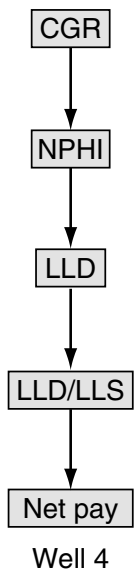

Well 4

Figure 3. Bayesian networks, constructed in each well. 


\begin{tabular}{|c|c|c|c|c|}
\hline \multirow{6}{*}{ 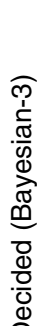 } & \multicolumn{4}{|c|}{ Actual output } \\
\hline & & 1 & 2 & 3 \\
\hline & 1 & $\Gamma 0.94$ & 0.00 & 0.007 \\
\hline & 2 & 0.06 & 0.04 & 0.00 \\
\hline & 3 & 0.00 & 0.96 & 0.00 \\
\hline & $C C R=$ & $=0.94$ & $\frac{0.04}{2}$ & $-0.00=0.49$ \\
\hline
\end{tabular}

(a) Well 1
Actual output

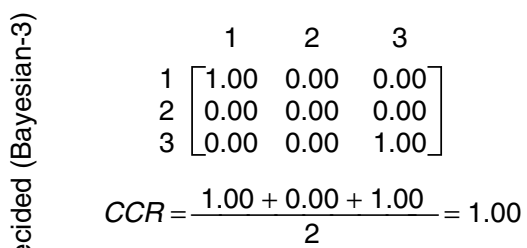

(b) Well 2

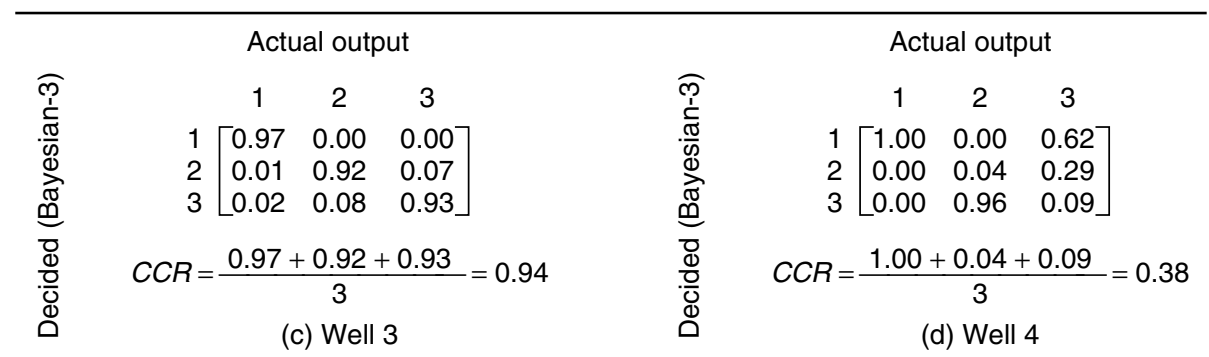

Figure 4. Confusion matrices and CCR values of determining productive zones by Bayesian-3 in all the wells.

\begin{tabular}{|c|c|c|c|c|c|c|c|}
\hline \multirow{6}{*}{ 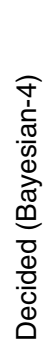 } & \multicolumn{3}{|c|}{ Actual output } & & \multicolumn{3}{|c|}{ Actual output } \\
\hline & 1 & 2 & 3 & \multirow{5}{*}{ 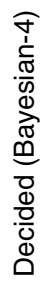 } & 1 & 2 & 3 \\
\hline & $1\lceil 0.51$ & 0.00 & 0.007 & & $1[0.69$ & 0.00 & 0.007 \\
\hline & 20.00 & $0.8 \mathrm{~s}$ & 0.00 & & 20.00 & 0.00 & 1.00 \\
\hline & 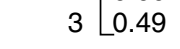 & 0.11 & 0.00 & & $3[0.31$ & 0.00 & 0.00 \\
\hline & \multicolumn{3}{|c|}{$C C R=\frac{0.51+0.89+0.00}{2}=0.70$} & & \multicolumn{3}{|c|}{$C C R=\frac{0.69+0.00+1.00}{2}=0.34$} \\
\hline \multirow{6}{*}{ 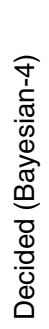 } & \multicolumn{3}{|c|}{ Actual output } & \multirow{6}{*}{ 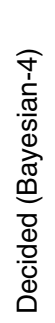 } & \multicolumn{3}{|c|}{ Actual output } \\
\hline & 1 & 2 & 3 & & 1 & 2 & 3 \\
\hline & $1\lceil 0.55$ & 0.00 & 0.007 & & $1[1.00$ & 0.00 & 0.007 \\
\hline & \begin{tabular}{l|l}
2 & 0.05
\end{tabular} & 1.00 & 0.89 & & \begin{tabular}{l|l}
2 & 0.00
\end{tabular} & 1.00 & 0.14 \\
\hline & $3\lfloor 0.41$ & 0.00 & $0.11]$ & & $3[0.00$ & 0.00 & 0.86 \\
\hline & $C C R=\frac{0.55+}{(C)}$ & $\begin{array}{r}1.00 \\
3 \\
\mathrm{We}\end{array}$ & $0.11=0.55$ & & $C C R=1.00$ & $\frac{-1.00}{3}$ & $0.86=0.95$ \\
\hline
\end{tabular}

Figure 5. Confusion matrices and CCR values of determining productive zones by Bayesian-4 in all the wells. 


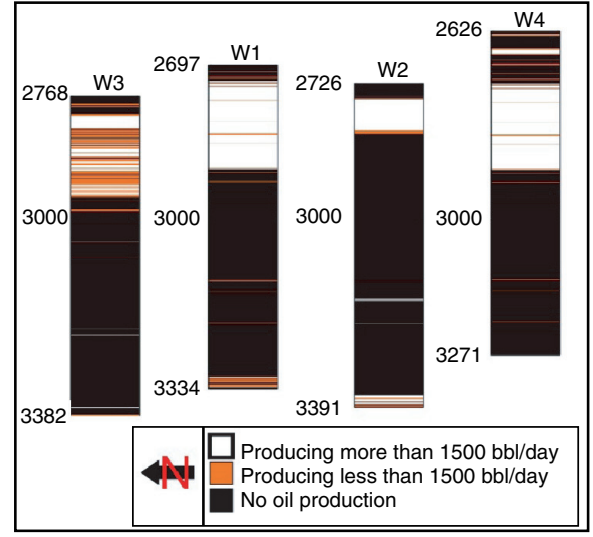

(a) Output of Bayesian-3

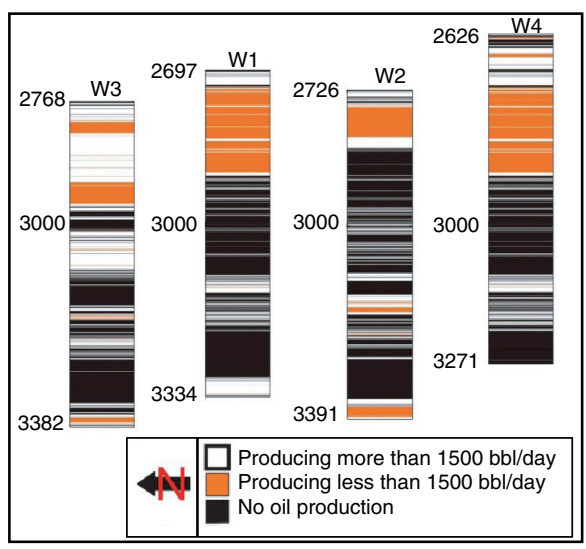

(b) Output of Bayesian-4

Figure 6. Classification of whole Sarvak interval by each Bayesian classifier due to $n p v$, modified after (Masoudi et al., 2012).

Here, the outputs of Bayesian classifiers are fused by a fuzzy integral to come to an agreement about the interval under investigation.

\subsection{Fusing classifiers}

There are several procedures to fuse outputs of different classifiers. Fuzzy theory serves an algorithm to do so. The methodology, used here is based on a fuzzy operator, called Sugeno discrete integral. The confusion matrices and CCR values resulted from fusing Bayesian classifiers by Sugeno integral are presented on Figure 7.

The output of Sugeno integral shows higher and more constant CCR values in comparison to CCR values of Bayesian outputs. Sarvak classification, based on fuzzy integral is presented on Figure 8. This classification is more similar to output of Bayesian-4 rather than Bayesian-3, even if it can be concluded that this is more optimistic than output of Bayesian classifiers.

\subsection{Comparing the results}

To compare preciseness of utilized methodologies, CCR values of each classifier corresponding to each well is plotted on the Figure 9. As it is obvious on this figure, CCR values of Sugeno output is the most constant value among all four methodologies, and always its value is more than $70 \%$. More constant CCR value more generalization ability, hence; Sugeno output has the highest generalization ability amongst others. On the other hand, Bayesian methods have local behavior. They show higher CCR values in the wells that they are trained in but less CCR values in wells, away from training well. Then; output of Sugeno integral is more certain than others. 


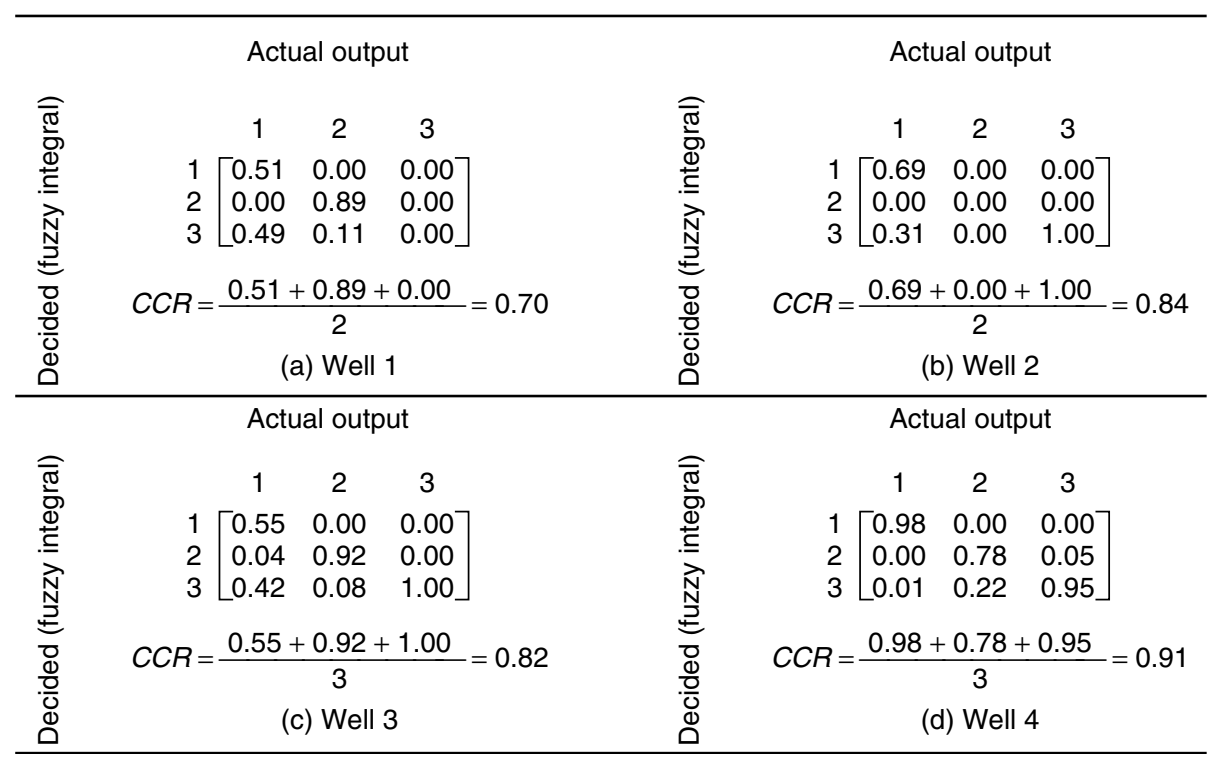

Figure 7. Confusion matrices and CCR values of determining productive zones resulted from fusing outputs of classifiers Bayesian- 3 and Bayesian- 4 by Sugeno discrete fuzzy integral in all the wells.

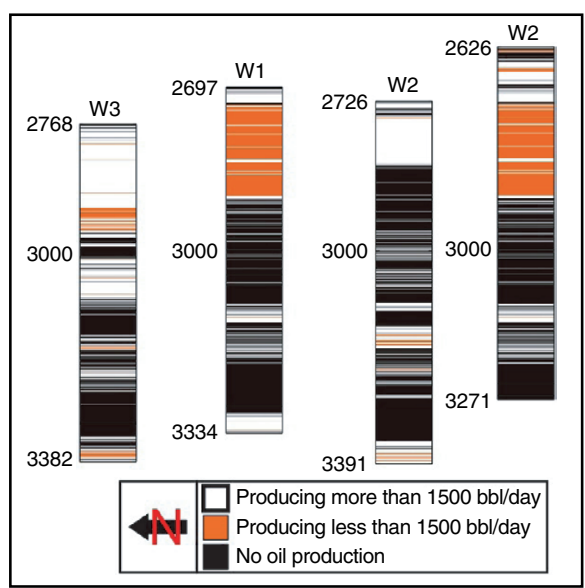

Figure 8. Classification of whole Sarvak interval by fusing Bayesian outputs, using fuzzy Sugeno integral due to $n p v$, modified after (Masoudi et al., 2012). 

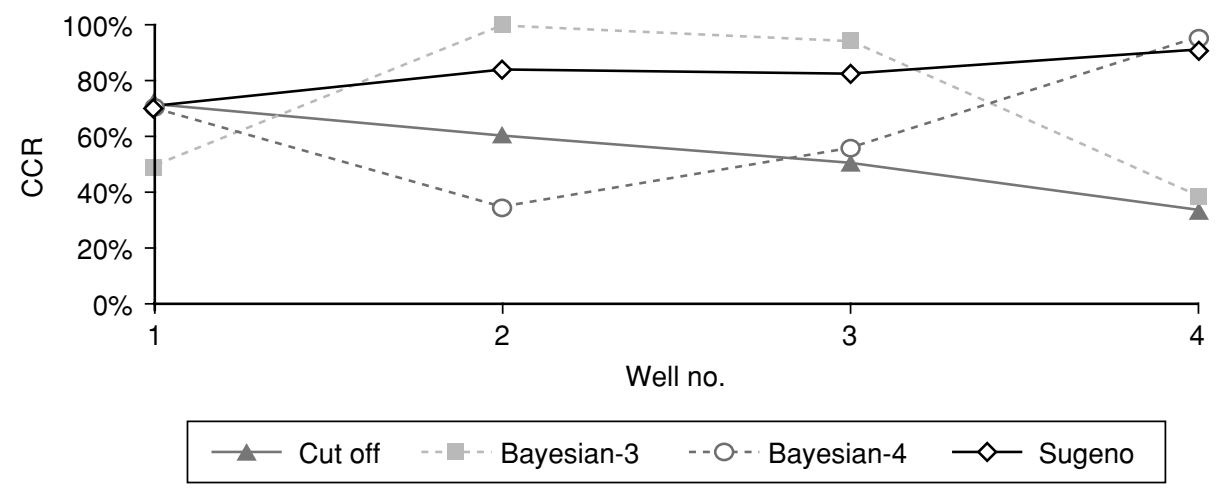

Figure 9. Confusion matrices and CCR values of determining productive zones resulted from fusing outputs, modified after (Masoudi et al., 2012).

\section{CONCLUSION}

To summarize the achievements of this work:

- Fuzzy fusion (Sugeno integral) is an applicable tool to fuse outputs of different classifiers to come on an agreement in determining productive zones. Due to Figure 9, CCR value of outputs of fuzzy integral always is ranked second, close to highest CCR value, then it can be said conservatively that this methodology is at least acceptable.

- Bayesian classifiers show local behavior, while by fusing their outputs, generalization ability increases significantly. In Figure 9, profiles of Bayesian3 and Bayesian-4 show high CCR values near training wells, and usually lower values farther away. But profile of Sugeno shows a relatively constant trend, which makes user confident about preciseness of this method in other wells.

- Sugeno integral shows the most optimistic output whereas Bayesian-3 shows the most pessimistic output. Output of Bayesian-4 is between these two extremes. According to Figure 6, Bayesian-4 classifies the larger portion of each well as productive zone in comparison to Bayesian-3, while as shown in Figure 8, Sugeno classifies the higher portion of the wells as high rate producing zone (white intervals) in comparison to Bayesian-4.

\section{ACKNOWLEDGMENT}

The authors wish to thank Exploratory Directorate of NIOC for providing data, and permission to publish the scientific results. 


\section{REFERENCES}

Cooke-Yarborqugh P., 1984. Reservoir Analysis By Wireline Formation Tester: Pressures, Permeabilities, Gradients And Net Pay. The Log Analyst 15(6), 36-46.

Darling T., 2005. Quicklook Log Interpretation, Well Logging and Formation Evaluation. Gulf Professional Publishing, Burlington, pp. 29-48.

Deakin M. and Manan W., 1998. The Integration of Petrophysical Data for the Evaluation of Low Contrast Pay, SPE Asia Pacific Conference on Integrated Modelling for Asset Management. Society of Petroleum Engineers, Inc., Kuala Lampur, Malaysia, 327-339.

Doguc O. and Ramirez-Marquez J.E., 2009. A generic method for estimating system reliability using Bayesian networks. Reliability Engineering \& System Safety 94(2), 542-550.

Duda R.O., Hart P.E. and Stork D.G., 2000. Bayesian Decision Theory, Pattern Classification, 2nd Edition.Wiley India Pvt. Ltd., pp. 68.

Flower J.G., 1983. Use of Sonic-Shear-Wave/Resistivity Overlay as a Quick-Look Method for Identifying Potential Pay Zones in the Ohio (Devonian) Shale. SPE Journal of Petroleum Technology 35(3), 638-642.

Grabisch M., Murofushi T. and Sugeno M., 1992. Fuzzy measure of fuzzy events defined by fuzzy integrals. Fuzzy Sets and Systems 50(3), 293-313.

Hassoun T.H., Zainalabedin K. and Minh C.C., 1997. Hydrocarbon Detection in LowContrast Resistivity Pay Zones, Capillary Pressure and ROS determination with NMR logging in Saudi Arabia. Middle East Oil Show and Conference, March 15-18, 1997. Society of Petroleum Engineers, Inc., Bahrain, pp. 127-143.

Howell E.P., Gutberlet S.S. and Glossa J.M., 1992. North Riley: Integrated Evaluation of a Heterogeneous Reservoir. Permian Basin Oil and Gas Recovery Conference, March 18-20, 1992. Midland, Texas, 227-236.

Jensen J.L. and Menke J.Y., 2006. Some Statistical Issues in Selecting Porosity Cutoffs for Estimating Net Pay. PetroPhysics 47(4), 315-320.

Johnson D.E. and Pile K.E., 2002. Formation Parameters. In: M.M. Patterson (Ed.), Well Logging in Nontechnical Language. Penn Well Publishing Company, Tulsa, pp. 25-44.

Joshi S. and Lahiri G., 1998. Integrated Reservoir Characterization of Neelam Field, SPE Asia Pacific Conference on Integrated Modelling for Asset Management, Kuala Lumpur, Malaysia, pp. 161-169.

Kuncheva L.L., 2004. Combining Pattern Classifiers, Methods and Algorithms. A Wiley-Interscience publication, Hoboken, pp. 350 .

Lauría E., 2008. An Information-Geometric Approach to Learning Bayesian Network Topologies from Data. In: D. Holmes and L. Jain (Eds.), Innovations in Bayesian Networks. Studies in Computational Intelligence. Springer Berlin, Heidelberg, pp. 187-217.

Masoudi P., Tokhmechi B., Zahedi A. and Jafari M.A., 2012. Developing a Method for Identification of Net Zones Using Log Data and Diffusivity Equation. Journal of Mining and Environment 2(1), 53-56. 
Masoudi, P., Tokhmechi, B., Bashari, A., Ansari Jafari, M., 2012. Identifying productive zones of Sarvak Formation by integrating outputs of different classification methods. Journal of Geophysics \& Engineering, 9(3), 282-290.

Masoudi P., Zahedi A., Moradzadeh A., Alirezaei F. and Zamanzadeh S.M., 2011. Estimation of in Place Hydrocarbon Volume in Multilayered Reservoirs Using Deterministic and Probabilistic Approaches. Energy Exploration and Exploitation 29(5), 543-558.

Mathur N., Raju S.V. and Kulkarni T.G., 2001. Improved Identification of Pay Zones through Integration of Geochemical and Log Data: A Case Study from Upper Assam Basin, India. AAPG Bulletin 85(2), 309-323.

Niedermayer D., 2008. An introduction to Bayesian networks and their contemporary applications. In: Holmes D.E. and Jain L.C. (Eds), Innovations in Bayesian Networks, Theory and Applications. Studies in computational intelligence. Springer, Springer, pp.117-130.

Singleton S., 2008. The use of seismic attenuation to aid simultaneous impedance inversion in geophysical reservoir characterization. The Leading Edge 27(3), 398-407.

Snyder R.H., 1971. A Review of the Concepts and Methodology of Determining "Net Pay". Fall Meeting of the Society of Petroleum Engineers of AIME. October 3-6, 1971. New Orleans, Louisiana, pp.1-12.

Svec R.K. and Grigg R.B., 2000. Reservoir Characterization and Laboratory Studies Assessing Improve Oil Recovery Methods for the Teague-Blinebry Field. SPE Permian Basin Oil and Gas Recovery Conference, March 21-23, 2000. Society of Petroleum Engineers Inc., Midland, Texas, pp.1-12.

Theodoridis S. and Koutroumbas K., 2003. Clustering Algorithms III: Schemes Based on Function Optimization, Pattern Recognition. Elsevier Academic Press, USA, 489-544.

Worthington P.F., 2000. Recognition and evaluation of low-resistivity pay. Petroleum Geoscience 6(1), 77-92.

Worthington P.F., 2008. The Application of Cutoffs in Integrated Reservoir Studies. SPE Reservoir Evaluation \& Engineering 11(6), 968-975.

Worthington P.F., 2010. Net Pay-What Is It? What Does It Do? How Do We Quantify It? How Do We Use It? SPE Reservoir Evaluation \& Engineering 13(5), 812-822.

Worthington P.F. and Cosentino L., 2005. The Role of Cut-offs in Integrated Reservoir Studies. SPE Reservoir Evaluation \& Engineering 8(4), 276-290. 
